\title{
A novel blunt dissection technique to treat modified deep anterior lamellar keratoplasty (DALK)-associated high astigmatism
}

\author{
Mohamed Elkadim ${ }^{1,2,3} \cdot$ James Myerscough ${ }^{1,2} \cdot$ Cristina Bovone ${ }^{1,2,4} \cdot$ Massimo Busin $\left(^{1,2,4}\right.$
}

Received: 21 May 2019 / Revised: 11 October 2019 / Accepted: 28 October 2019 / Published online: 21 November 2019

(c) The Author(s), under exclusive licence to The Royal College of Ophthalmologists 2019

\begin{abstract}
Objectives To describe a new surgical technique to correct a high astigmatism following modified deep anterior lamellar keratoplasty (DALK) and to evaluate the associated clinical outcomes.

Methods Retrospective interventional case series included eyes with high astigmatism following modified DALK performed between July 2012 and June 2016. The prevalence of keratometric astigmatism (KA) higher than 4.5 diopters (D) was evaluated after complete suture removal. Surgical correction was obtained by opening the surgical wound at the steeper meridian and carrying out a blunt dissection at the graft-host surface of contact under keratoscopic control. KA, Refractive astigmatism (RA), and best spectacle-corrected visual acuity (BSCVA) were measured preoperatively and at 1, 12, and 24 months postoperatively. Vector analysis of 1 year change in KA was performed.

Results High astigmatism was found in 47 of 511 eyes $(9.2 \%)$. KA (mean \pm standard deviation [SD]) decreased from $7.67 \pm$ 2.78 to $3.10 \pm 1.37 \mathrm{D}$ at 1 month after astigmatic correction $(p<0.001)$ with no subsequent significant change. Vector analysis of 1 year change in KA: surgically induced astigmatism was $5.30 \pm 3.29 \mathrm{D}$ and mean absolute angle of error was $6.97 \pm 4.25^{\circ}$. BSCVA improved from $0.21 \pm 0.20 \log$ MAR preoperatively to $0.11 \pm 0.13 \log$ MAR $(p<0.001)$; RA decreased from $6.32 \pm 2.56$ to $2.61 \pm 1.05 \mathrm{D}(p<0.001)$. No intra- or post-operative complications occurred.

Conclusions High astigmatism is present in $<10 \%$ of cases after modified DALK and can be effectively managed by means of blunt relaxing dissection at the graft-host junction.
\end{abstract}

\section{Introduction}

Deep anterior lamellar keratoplasty (DALK) is increasingly favored over penetrating keratoplasty (PK) in the management of corneal ectasia and other diseases of the corneal

Supplementary information The online version of this article (https:// doi.org/10.1038/s41433-019-0686-6) contains supplementary material, which is available to authorized users.

Massimo Busin

mbusin@yahoo.com

1 Ospedale Privato "Villa Igea", Department of Ophthalmology, Forlì, Italy

2 Istituto Internazionale per la Ricerca e Formazione in Oftalmologia (IRFO), Forlì, Italy

3 Faculty of Medicine, Department of ophthalmology, Tanta University, Tanta, Egypt

4 Department of Morphology, Surgery and Experimental Medicine, University of Ferrara, Ferrara, Italy stroma [1]. Despite progress in the refinement and standardization of DALK technique, postoperative high astigmatism remains a leading cause of limited visual recovery [2].

Relaxing incisions correct postkeratoplasty astigmatism by flattening the steep meridian, but have been demonstrated to produce unpredictable results $[3,4]$. In addition, to maximize their effect, incisions must be as deep as possible; therefore with the vertical wound of conventional DALK, there is a significant risk of wound gape and perforation [4].

As we previously described [5], in a modified $9 \mathrm{~mm}$ DALK with clearance of the deep stroma limited to the central $6 \mathrm{~mm}$, the host bed includes a peripheral shoulder of deep stroma, $1.5 \mathrm{~mm}$ in width, surrounding the central $6 \mathrm{~mm}$ optical zone (Fig. 1a). As a result, the shoulder creates a step for $360^{\circ}$ allowing the surgeon to open the DALK wound all the way up to the recipient peripheral stroma, as well as bluntly dissecting the donor from the recipient stromal tissue in the area to be relaxed, while minimizing the risk of gape or perforation. 
The aim of this study was to assess the incidence of high astigmatism following this modified DALK technique, as well as evaluate the feasibility of exploiting this unique wound construction for effective and safe surgical astigmatic correction.

\section{Methods}

All eyes with high astigmatism (Keratometric Astigmatism [KA] > 4.5 Diopters [D] 1 month after complete suture removal) following modified DALK performed between July 2012 and June 2016 at "Villa Igea" Hospital (Forlì, Italy) were included. The study followed the tenets of the Declaration of Helsinki and was approved by the local ethics committee (Comitato Etico Ospedali Privati Villa Serena-Villa Igea); informed consent was obtained from all patients undergoing surgery. All patients had undergone surgery initially with a previously described standardized technique (Fig. 1a), including transplantation of a $9 \mathrm{~mm}$ graft and central baring of a $6 \mathrm{~mm}$ optical zone of the preDescemet's layer [5]. Patients who underwent cataract surgery during the follow-up period were excluded.

\section{Surgical technique}

In all patients, anesthesia and akinesia were obtained by means of peribulbar injection of $10 \mathrm{ml}$ of a $0.75 \%$ ropivacaine solution. The axis of the steep meridian was identified using first the preoperative keratometric readings and then intraoperatively confirmed with microscopic mounted keratoscopy. The graft-host junction was vertically entered with the tip of a Sinesky hook and opened to the full depth of the initial wound (Fig. 1b). The wound was extended to 1 clock hour $\left(30^{\circ}\right)$. The graft edge was then slightly elevated with curved tying forceps (Moria, France) and the Sinesky hook was inserted into the horizontal plane between the graft and the underlying posterior host stromal peripheral rim. The hook was advanced centripetally by $1.5 \mathrm{~mm}$ along the extent of the $30^{\circ}$ wound to achieve complete dehiscence of the graft-host interface (Fig. 1c). Care was taken to not advance the hook centripetally beyond the posterior stromal crown of $1.5 \mathrm{~mm}$ diameter, and not to press on the stromal bed but indeed slightly elevate the graft. This distance of $1.5 \mathrm{~mm}$ is visually evident by the slightly increased reflectivity seen in the peripheral area in which there is graft/host stromal overlap. This procedure was repeated at $180^{\circ}$ from the center of the initial incision. The resulting astigmatic correction was evaluated intraoperatively using microscope mounted keratoscopy (Leica, Germany). A ring of LED light is projected onto the cornea and its reflection is viewed through the microscope. If the correction was deemed insufficient, the dehiscence was increased to a maximum of 2 clock hours $\left(60^{\circ}\right)$ within both incisions (Video 1 ).

Antibiotic eye ointment (tetracycline $1 \%$ and sulfamethoxazole 5\% in combination, SIFI, Catania, Italy) was applied and the eye was patched for $2 \mathrm{~h}$ postoperatively. All patients were given topical metilmicin $(0.3 \%)$ and dexamethasone $(0.1 \%)$ (SIFI, Catania, Italy) combination therapy every $2 \mathrm{~h}$ until re-epithelialization was complete, and then four times a day for 1 week. All patients were seen postoperatively at day 1 and 2 , as well as 1 week postoperatively. Further postoperative follow-up examinations were scheduled at $1,6,12$, and 24 months.

\section{Outcome measures}

The primary outcome measure was KA, determined by means of anterior segment OCT (AS-OCT) (Casia; Tomey, Tokyo, Japan). Secondary outcomes included: 1) Best spectaclecorrected visual acuity (BSCVA) recorded using a Snellen chart and converted into the logarithm of the minimum angle
Fig. 1 a Wound configuration of modified $9 \mathrm{~mm}$ DALK with baring of only the central $6 \mathrm{~mm}$ of the pre-Descemet's layer. Blunt dissection at the graft-host interface; b Vertical; c Horizontal blunt dissection under the graft
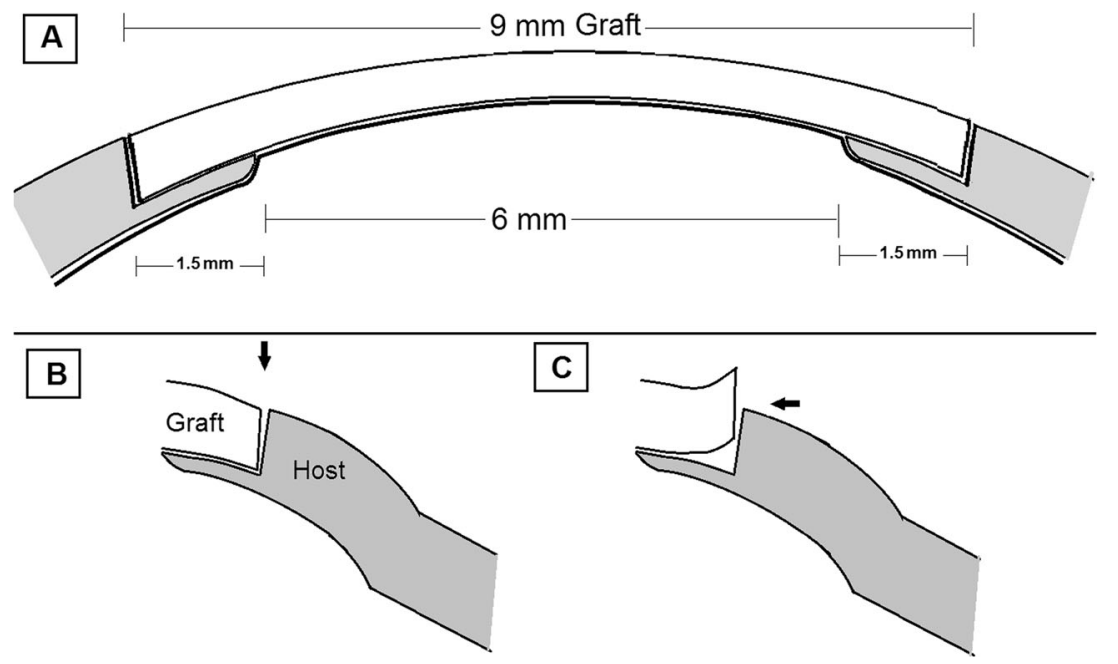
of resolution (logMAR) scale for statistical purposes; 2) Refractive astigmatism (RA); 3) Complications.

\section{Astigmatism analysis}

The pre- and 1 year post-operative mean KA values were compared and vector analysis of the astigmatic change was performed using the Alpins method [6]. The target outcome used in calculations was considered to be zero astigmatism. The steep meridian axis was considered the axis of astigmatism. Mathematical calculations were done using Excel 2007 software (Microsoft Corp.). The results of vector analysis were presented using single-angle polar plots (Supplementary Material 1) for the target-induced astigmatism vector (TIA) (i.e., the intended surgical astigmatic change) versus the surgically induced astigmatism vector (SIA): (i.e., the actual astigmatic change induced). The difference vector (DV): (i.e., the difference between SIA and TIA by magnitude and axis), and the correction index (CI) the ratio of the SIA (actual effect) to TIA (target effect) [7] were also calculated. The flattening effect (FE) (i.e., the effective proportion of SIA at the intended meridian), torque effect (the amount of SIA that has been ineffective in reducing astigmatism at the intended meridian but has caused axis rotation), and the flattening index (i.e., the ratio between the FE and TIA) were also calculated [8].

Since the target outcome was considered to be zero astigmatism, the value of TIA was equal to the value of preoperative astigmatism, and the value of the DV was equal to the postoperative astigmatism [9].

\section{Statistical analysis}

Statistical analysis was performed using SPSS Statistics Version 16 (IBM, Armonk, New York, USA). Continuous variables were reported as mean \pm standard deviation (SD).
Wilcoxon signed-rank test was used for comparing preoperative and postoperative measures. Correlations were examined with Pearson's correlation co-efficient and Spearman rank-correlation test. $p$ values $<0.05$ were considered statistically significant.

\section{Results}

Forty-seven (9.2\%) of five hundred and eleven eyes that had undergone modified DALK were found to have KA>4.5 D 1 month after complete suture removal, thus requiring surgical astigmatic correction. KA was higher than $6 \mathrm{D}$ in 26 of 511 eyes $(5.1 \%)$. Due to incomplete follow-up (six eyes) or cataract surgery (one eye), seven eyes were excluded from the analysis of astigmatic correction.

The age of patients in years (mean \pm SD) averaged $42.2 \pm 40$, ranging from 18 to 76 . The indication for DALK surgery was keratoconus in $27(67.5 \%)$ eyes and stromal opacity in $13(32.5 \%)$ eyes. The mean time interval between DALK and astigmatic correction surgery was $15.6 \pm$ 2.9 months. All eyes had at least 1 year of follow-up and 12 (30\%) eyes completed a 2-year follow-up.

$\mathrm{KA}($ mean $\pm \mathrm{SD})$ decreased significantly $(p<0.001)$ from $7.67 \pm 2.78 \mathrm{D}$ preoperatively to $3.10 \pm 1.37 \mathrm{D}$ as early as 1 month after astigmatic correction; it remained stable at later examination times with no further significant change (Table 1). After astigmatic correction, 35 of 40 eyes $(87.5 \%)$ had KA lower than 5 D.

Vector analysis of the change in KA 1 year after astigmatic correction is summarized in Table 2; The SIA (mean $\pm \mathrm{SD}$ ) was $5.30 \pm 3.29 \mathrm{D}$, with a significant correlation between the TIA and the SIA (Pearson's $r=0.75, p<$ 0.001 , Fig. 2). The geometric mean of CI (SIA/TIA) was 0.61 , indicating under-correction. There was a moderately positive correlation between TIA and DV $(p=0.001$,
Table 1 Preoperative and postoperative $(1,12$, and 24 months) keratometric astigmatism, refractive astigmatism and best spectaclecorrected visual acuity

\begin{tabular}{|c|c|c|c|c|c|}
\hline & \multicolumn{4}{|c|}{ Mean \pm standard deviation (range) } & \multirow{2}{*}{$\begin{array}{l}p \text { value }^{\mathrm{a}} \\
\text { preoperative versus } \\
1 \text { month }\end{array}$} \\
\hline & Preoperative & 1 month & 12 months & 24 months & \\
\hline Number of eyes & 40 & 40 & 40 & 12 & \\
\hline KA (D) & $\begin{array}{l}7.67 \pm 2.78 \\
(4.6-16.4)\end{array}$ & $\begin{array}{l}3.10 \pm 1.37 \\
(0.6-6.2)\end{array}$ & $\begin{array}{l}3.39 \pm 1.48 \\
(0.6-7.1)\end{array}$ & $\begin{array}{l}3.08 \pm 1.09 \\
(1.3-4.7)\end{array}$ & $<0.001$ \\
\hline RA (D) & $\begin{array}{l}6.32 \pm 2.56 \\
(5-14)\end{array}$ & $\begin{array}{l}2.50 \pm 0.96 \\
(0.5-5)\end{array}$ & $\begin{array}{l}2.61 \pm 1.05 \\
(1-6)\end{array}$ & $\begin{array}{l}2.54 \pm 1.2 \\
(1-4.5)\end{array}$ & $<0.001$ \\
\hline $\begin{array}{l}\text { BSCVA } \\
\text { (LogMAR) }\end{array}$ & $\begin{array}{l}0.21 \pm 0.20 \\
(-0.08 \text { to } 0.7)\end{array}$ & $\begin{array}{l}0.077 \pm 0.14 \\
(0-0.7)\end{array}$ & $\begin{array}{l}0.11 \pm 0.13 \\
(-0.08 \text { to } 0.4)\end{array}$ & $\begin{array}{l}0.088 \pm 0.076 \\
(0-0.22)\end{array}$ & $<0.001$ \\
\hline $\begin{array}{l}\text { Mean BSCVA } \\
\text { (Snellen) }\end{array}$ & $20 / 32$ & $20 / 23$ & $20 / 25$ & $20 / 24$ & \\
\hline
\end{tabular}

$B S C V$ best spectacle-corrected visual acuity, $D$ diopters, $K A$ keratometric astigmatism, LogMAR logarithm of minimal angle of resolution, $R A$ refractive astigmatism

${ }^{\mathrm{a}}$ No significant difference was found between 1, 12, and 24 months results 
Table 2 Vector analysis of changes in keratometric astigmatism after 1 year using Alpins method

\begin{tabular}{lcl}
\hline Parameter & Mean \pm SD & Range \\
\hline TIA (D) & $7.67 \pm 2.78$ & $4.60-16.40$ \\
SIA (D) & $5.30 \pm 3.29$ & $1.02-16.10$ \\
DV (D) & $3.39 \pm 1.48$ & $0.60-7.10$ \\
ME (D) & $-2.37 \pm 2.19$ & -6.64 to 5.22 \\
CI (geometric mean) & $0.61 \pm 0.28$ & $0.16-1.52$ \\
AE (degrees) & $-0.43 \pm 8.32$ & -21.95 to 14.01 \\
Absolute AE (degrees) & $6.97 \pm 4.25$ & $1.05-21.95$ \\
TE (D) & $0.16 \pm 1.56$ & -2.69 to 4.44 \\
FE (D) & $5.11 \pm 3.22$ & $0.88-16.03$ \\
FI (geometric mean) & $0.58 \pm 0.27$ & $0.16-1.47$ \\
IOS (geometric mean) & $0.42 \pm 0.18$ & $0.09-0.84$
\end{tabular}

$A E$ angle of error, $C I$ correction index, $D V$ difference vector, $F E$ flattening effect, $F I$ flattening index, $I O S$ index of success, $M E$ magnitude of error, SIA surgically induced astigmatism, $S D$ standard deviation, $T E$ torque effect, TIA target-induced astigmatism

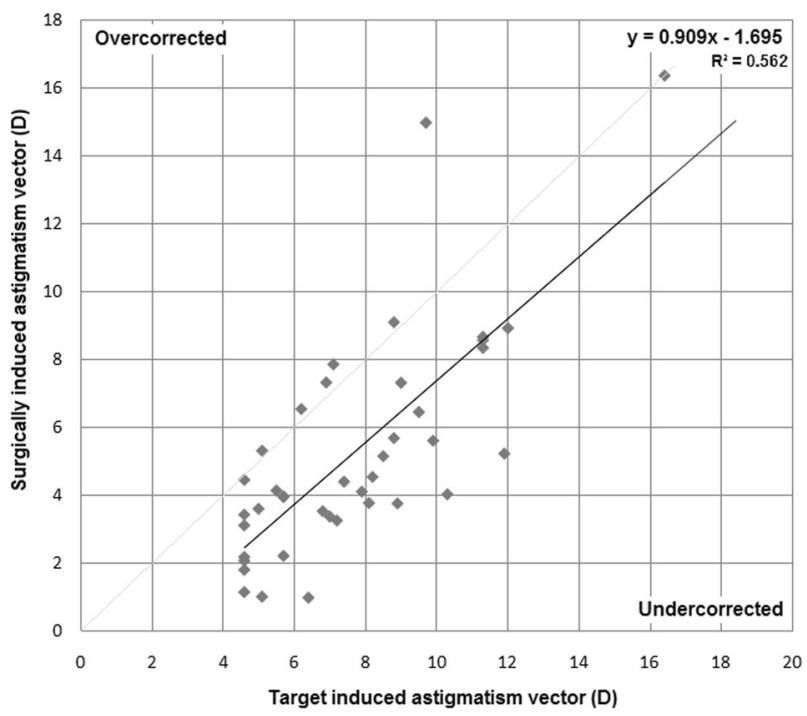

Fig. 2 Scatter plot of surgically induced astigmatism (SIA) versus Target-induced astigmatism (TIA) at 1 year

Pearson's $r=0.44)$, i.e., the higher the TIA value was the higher the degree of subsequent under-correction recorded. The magnitude of error (mean $\pm \mathrm{SD}$ ) was $-2.37 \pm 2.19 \mathrm{D}$ and it was positive in six eyes $(15 \%)$, with only one eye $(2.5 \%)$ having a magnitude of error $>0.8 \mathrm{D}$.

The angle of error ranged from -21.95 to $14.01^{\circ}$, with $97.5 \%$ of cases in-between -15 to $15^{\circ}$. This small angle of error resulted in a minimal torque effect $($ mean $\pm \mathrm{SD})$ of $0.16 \pm 1.56 \mathrm{D}$.

BSCVA (mean \pm SD) improved from $0.21 \pm 0.20$ logMAR to $0.11 \pm 0.13$ at 1 year $(P<0.001)$. RA (mean \pm SD) decreased from $6.32 \pm 2.56$ to $2.61 \pm 1.05 \mathrm{D}$ at 1 year $(P<$ $0.001)$. No intra- or post-operative complications occurred.

\section{Discussion}

Following DALK surgery, most patients achieve satisfactory visual outcomes with relatively rare complications. Most reports do not specifically address the issue of high post-DALK astigmatism and usually report mean keratometric outcomes rather than the percentage of patients experiencing high astigmatism beyond the possibility of spectacle correction. In a recent large series [10], up to $11 \%$ of patients were found to have a high post-DALK astigmatism, that could not be corrected with spectacles. Furthermore, in this series astigmatism was arbitrarily considered high when it exceeded 6 D instead of the more conventional value of 4-4.5 D [10]. Our series compares favorably with these results, with astigmatism $>4.5 \mathrm{D}$, being recorded in $9.2 \%$ and $>6 \mathrm{D}$ in only $5.1 \%$ of eyes, thus halving the percentage of highly astigmatic post-DALK eyes. Most probably, this is a consequence of the larger diameter of the donor grafts employed, i.e., $9 \mathrm{~mm}$ instead of the conventional $8-8.5 \mathrm{~mm}$. Increasing the diameter of DALK grafts may theoretically expose the patients to a higher risk of immunologic rejection and possible graft failure. However, we recently reported that the rate of stromal rejection after 9-mm DALK is comparable with the rate published for conventional DALK, regardless of the indication for surgery [11] and therefore we advocate its use given its refractive superiority [12]. Since much of the intraoperative perforation encountered during DALK is peripheral, leaving a peripheral rim of stroma minimizes this risk, and has also been reported to prevent Descemet's membrane wrinkles in cases with advanced keratoconus [13].

Various interventions have been reported to treat high astigmatism in post-DALK eyes. Relaxing incisions, either manual $[14,15]$ or femto-assisted [16], have shown rather unpredictable outcomes $[4,17]$. Intrastromal corneal ring segments [18] and Photorefractive keratectomy [19] have been reported but only in the partial correction of low astigmatism. Lens based refractive options such as either phakic or in-the-bag toric intraocular lenses have been described following PK and DALK [20, 21], but expose the patient to the risks of an intraocular procedure.

In terms of treatment efficacy, relaxing incisions with or without augmentation with compression sutures have shown reduction of KA of 42-60\% [14, 15, 22-24], with which our series performs comparably. Our reduction in KA of $56 \%$ is without the use of compression sutures, which often break or require removal so are not a permanent solution, although the longer term follow-up of such cases tends not to be reported. Furthermore, the correlation we observed between SIA and TIA is in keeping with other published series [22, 24], indicating that the intraoperative 
keratoscopic titration we use is sufficiently accurate, without being guided by a nomogram.

Intraoperative keratoscopy also reduces the rate of overcorrection in our series. In fact, overcorrection of up to $35 \%$ is reported following relaxing incisions for postDALK astigmatism [16, 22], whereas our technique has a tendency towards under-correction (mean $\mathrm{CI}=0.61$ ). Such cases of under-correction may display a more aggressive interface fibrotic response, diminishing the effect of blunt dissection, possibly related to the initial pathology being inflammatory such as post-herpetic rather than ectatic. This variable of astigmatic predictability by etiology might be interesting to investigate further in future. In addition, our technique of centripetal dissection along the recipient bed to augment the desired effect may explain why the absolute angle of error of $6.97 \pm 4.25^{\circ}$ was much lower in our series than in previous reports $\left(19.5 \pm 16.3^{\circ}\right)$ from series employing longer (up to $90^{\circ}$ ) incisions [22]. Finally, the 1year improvement in BSCVA (to mean $0.11 \pm 0.13$ logMAR) compares favorably with previously published series $[15,24]$.

With regards to intraoperative complications, even when assisted by femtosecond laser, conventional relaxing incisions still carry significant risk of perforation $[15,22,25,26]$. Our technique exploits the opportunity to perform consistently deep, uniform arcuate dissection, whilst minimizing the risk of perforation, as evidenced by no single episodes of perforation in our series. Postoperatively, there was no significant regression in our series, with outcomes at one month being no different to those at one or even 2 years ( $p=0.94$ and 0.58 , respectively). This is probably because we intentionally cause significant wound dehiscence at the steep meridian by centripetally extending the wound dissection in the horizontal plane, and because we do not use compression sutures which can cheese wire over time reducing their efficacy.

In conclusion, modified DALK has a low prevalence of postoperative high astigmatism which can be effectively managed surgically by means of blunt relaxing dissection at the stepped graft-host junction. The refractive impact of the technique is immediate and remains stable at 2 years postoperatively.

\section{Summary}

\section{What was known before}

- Described techniques to manage high postkeratoplasty astigmatism are unpredictable and carry significant risk of complications.

\section{What this study adds}

- High astigmatism after modified DALK is infrequent and can be easily corrected using blunt relaxing dissection technique.

- Blunt dissection within the stepped graft-host junction produces a stable refractive outcome whilst minimizing intraoperative complications.

\section{Compliance with ethical standards}

Conflict of interest The authors declare that they have no conflict of interest.

Publisher's note Springer Nature remains neutral with regard to jurisdictional claims in published maps and institutional affiliations.

\section{References}

1. Wisse RPL, Van Den Hoven CML, Van Der Lelij A. Does lamellar surgery for keratoconus experience the popularity it deserves? Acta Ophthalmol. 2014;92:473-7.

2. Liu H, Chen Y, Wang P, Li B, Wang W, Su Y, et al. Efficacy and safety of deep anterior lamellar keratoplasty vs. penetrating keratoplasty for keratoconus: a meta-analysis. PLoS ONE 2015;10: e0113332.

3. Chang S-M, Su C-Y, Lin C-P. Correction of astigmatism after penetrating keratoplasty by relaxing incision with compression suture: a comparison between the guiding effect of photokeratoscope and of computer-assisted videokeratography. Cornea. 2003;22:393-8.

4. Ho Wang Yin G, Hoffart L. Post-keratoplasty astigmatism management by relaxing incisions: a systematic review. Eye Vis. 2017;4:29.

5. Busin M, Leon P, Nahum Y, Scorcia V. Large $(9 \mathrm{~mm})$ deep anterior lamellar keratoplasty with clearance of a 6-mm optical zone optimizes outcomes of keratoconus surgery. Ophthalmology. 2017;124:1072-80.

6. Alpins NA, Goggin M. Practical astigmatism analysis for refractive outcomes in cataract and refractive surgery. Surv Ophthalmol. 2004:49:109-22.

7. Reinstein DZ, Archer TJ, Randleman JB. JRS standard for reporting astigmatism outcomes of refractive surgery. J Refract Surg. 2014;30:654-9.

8. Alpins NA. Vector analysis of astigmatism changes by flattening, steepening, and torque. J Cataract Refract Surg. 1997;23:1503-14.

9. Alpins N. Astigmatism analysis by the Alpins method. J Cataract Refract Surg. 2001;27:31-49.

10. Romano V, Iovieno A, Parente G, Soldani AM, Fontana L. Longterm clinical outcomes of deep anterior lamellar keratoplasty in patients with keratoconus. Am J Ophthalmol. 2015;159:505-11.

11. Giannaccare G, Weiss JS, Sapigni L, Bovone C, Mattioli L, Campos EC, et al. Immunologic stromal rejection after deep anterior lamellar keratoplasty with grafts of a larger size $(9 \mathrm{~mm})$ for various stromal diseases. Cornea. 2018;37:967-72.

12. Huang $\mathrm{T}, \mathrm{Hu} \mathrm{Y}$, Gui M, Zhang H, Wang Y, Hou C. Largediameter deep anterior lamellar keratoplasty for keratoconus: visual and refractive outcomes. Br J Ophthalmol. 2015;99:1196-200.

13. Khakshoor H, Eslampoor A, Rad SS, Vejdani A. Modified deep anterior lamellar keratoplasty for the treatment of advanced 
keratoconus with steep corneal curvature to help in eliminating the wrinkles in the Descemet's membrane. Indian $\mathrm{J}$ Ophthalmol. 2014;62:392-5.

14. Javadi MA, Feizi S, Mirbabaee F. Relaxing incisions combined with adjustment sutures for post-deep anterior lamellar keratoplasty astigmatism in keratoconus. Cornea. 2009;28:1130-4.

15. Javadi MA, Feizi S, Mirbabaee F, Fekri Y. Office based relaxing incision procedure for correction of astigmatism after deep anterior lamellar keratoplasty. J Ophthalmic Vis Res. 2017;12:156-64.

16. anNakhli F, Khattak A. Vector analysis of femtosecond laser-assisted astigmatic keratotomy after deep anterior lamellar keratoplasty and penetrating keratoplasty. Int Ophthalmol. 2019;39:189-98.

17. Bayramlar H, Karadag R, Cakici O, Ozsoy I. Arcuate keratotomy on post-keratoplasty astigmatism is unpredictable and frequently needs repeat procedures to increase its success rate. Br J Ophthalmol. 2016;100:757-61.

18. Arantes JCD, Coscarelli S, Ferrara P, Araújo LPN, Ávila M, Torquetti L. Intrastromal corneal ring segments for astigmatism correction after deep anterior lamellar keratoplasty. J Ophthalmol. 2017;2017:8689017.

19. Leccisotti A. Photorefractive keratectomy with mitomycin $\mathrm{C}$ after deep anterior lamellar keratoplasty for keratoconus. Cornea. 2008;27:417-20.

20. Schiano Lomoriello D, Savini G, Naeser K, Colabelli-Gisoldi RM, Bono V, Pocobelli A. Customized toric intraocular lens implantation in eyes with cataract and corneal astigmatism after deep anterior lamellar keratoplasty: a prospective study. J Ophthalmol. 2018;2018:1649576.

21. Wade M, Steinert RF, Garg S, Farid MGR. Results of toric intraocular lenses for post-penetrating keratoplasty astigmatism. Ophthalmology. 2014;121:771-7.

22. Kubaloglu A, Coskun E, Sari ES, Gune AS, Cinar Y, Piero DP, et al. Comparison of astigmatic keratotomy results in deep anterior lamellar keratoplasty and penetrating keratoplasty in keratoconus. Am J Ophthalmol. 2011;151:637-43.

23. Fares U, Mokashi AA, Al-Aqaba MA, Otri AM, Miri A, Dua HS. Management of postkeratoplasty astigmatism by paired arcuate incisions with compression sutures. Br J Ophthalmol. 2013;97: 438-43.

24. Koay PYP, McGhee CNJ, Crawford GJ. Effect of a standard paired arcuate incision and augmentation sutures on postkeratoplasty astigmatism. J Cataract Refract Surg. 2000;26: 553-61.

25. Bahar I, Levinger E, Kaiserman I, Sansanayudh W, Rootman DS. IntraLase-enabled astigmatic keratotomy for postkeratoplasty astigmatism. Am J Ophthalmol. 2008;146:897-904.e1.

26. Hashemian MN, Ojaghi H, Mohammadpour M, Jabbarvand M, Rahimi F, Abtahi M-A, et al. Femtosecond laser arcuate keratotomy for the correction of postkeratoplasty high astigmatism in keratoconus. J Res Med Sci. 2017;22:17. 